\title{
Teaching and Learning at Scale: Foundations
}

\author{
Patrick McAndrew
}

The Open University (OU) offered a radical change in how higher education was considered in the UK from the 1960s. A fundamental change was to allow access to those who wanted to learn, without their needing to show prior success in qualifications. Alongside this expansion in offering access there also needed to be a rethink in how learning could operate at scale. Higher education has a tradition of individual responsibility that was not suited to the complexity of the task, rather the OU needed to take a team approach to designing, building and operating the learning experience.

Addressing such complexity is one part of the model in Beyond Prototypes (introduced briefly in Chapter 1), recognising the complexity that occurs when applying Technology Enhanced Learning (TEL). Each part of the model can be seen to act in the development of the OU: persistence in achieving the aims of the $O U$ to meet the needs of a new body of students; bricolage in being prepared to experiment with new ideas and new technologies; and, an underlying dependence on evidence to help understand and address the problems that are faced at scale.

How to cite this book chapter:

McAndrew, P. 2019. Teaching and Learning at Scale: Foundations. In: Ferguson, R., Jones, A. and Scanlon, E. (eds). Educational Visions: Lessons from 40 years of innovation. Pp. 13-32. London: Ubiquity Press. DOI: https://doi.org/10.5334/bcg.b. License: CC-BY 4.0 


\section{Beyond Prototypes}

The Beyond Prototypes model sets out four different aspects of innovations that are summarised in the report (Scanlon et. al., 2013):

1. The TEL complex

"TEL involves a complex system of technologies and practices. In order to embed significant TEL innovation successfully, it is necessary to look beyond product development and pay close attention to the entire process of implementation."

2. Persistent intent

"Significant innovations are developed and embedded over periods of years rather than months. Sustainable change is not a simple matter of product development, testing and roll-out."

3. Bricolage

"TEL innovation is a process of bricolage. This process includes informed and directed exploration of the technologies and practices required to achieve an educational goal. It involves experimentation to generate fresh insights, and a creative use of available resources. It also requires engagement with a range of communities and practices."

4. Evidence

"Successful implementation of TEL innovation requires evidence that the projected educational goal has been achieved. Reliable evaluations must be carried out; their findings must be disseminated and acted on. Methods of evaluation are required that can be applied to processes of innovation and to institutional change, as well as those that can be applied to shifts in technology usage." (Scanlon et al, 2013, p6-7]

\section{Considering the OU through the Beyond Prototypes framework}

In this chapter those four aspects of the Beyond Prototypes model emerge from the work of the OU, including the Computers and Learning research group (CALRG) as part of the Institute of Educational Technology (IET).

The challenge of forming the first modern open university was undeniably complex, and the solutions proposed recognised both the complexity in the situation and also space for further development. The first section of this chapter considers how complexity was addressed by those working to bring the university together as they thought through how teamwork, and the role that educational technology needs to play, could work in practice.

In the second section the persistence of the work is considered. In particular considering how the university addressed the challenge of being open to 
learners. One of the fundamentals of the approach to distance education taken by The Open University is its open entry system. Open entry allows anyone to choose to study any subject that is offered. There are no prerequisites; at one stage this also meant that students could choose to study at different levels (though the fee system now in place makes that choice much more limited). This does not mean though that all choices will lead to equal success or that success can be measured on the same basis for all learners. Over time systemic threats to operation have occurred driven from funding models that have impacted unfairly on the part-time sector. These pressures have meant the OU has needed to show persistence in remaining true to its mission and yet avoid the complacency inherent in being a market-leader.

The third element is experimentation; "bricolage". The OU arose through a process of experimentation and willingness to try alternative approaches to support students to learn at a distance. The Open University came into operation at a time when new tools and new ways of thinking were available to reconsider the way correspondence education worked, and so provide a fuller experience of distance education that would be accepted as comparable to that from more conventional higher education providers. Being prepared to try new approaches has been very successful, however there are also risks in then settling into an accepted approach and providing a legacy position. The difficulty of being an innovator from a dominant position is recognised (Rogers, 1995) and can lead to susceptibility to losing position to other more disruptive innovators. At several points in the OU's history such disruption has threatened, as technology offered alternative ways for other providers to operate without the investment at scale of the OU. Nonetheless, the OU remains the leading distance and part-time provider of higher education in the UK. This is in part due to a willingness to itself disrupt its own models for working.

The fourth component of the Beyond Prototypes model is evidence. The OU established an evidence-based approach from the beginning, driven by the need to prove the quality of its approach and show value. Through research mainly carried out in the Institute of Educational Technology, the OU has always surveyed its students at scale and monitored the performance and satisfaction of its students. The role of evidence has been refreshed in more recent years through the availability and use of analytic measures.

\section{Meeting complexity through teams at the OU}

The establishment of The Open University arose out of a mix of political and practical ambitions in the 1960s that made its existence at first uncertain for reasons that included "demand was not proven, many students would leave early and degree-level work could not be taught in such a way" (Weinbren, $2015, \mathrm{p} 11)$. On the other hand, there had been considerable thought and planning into the idea of the OU, with the ideas captured in the original Planning 
Report (HMSO, 1969). That report set out the different components of OU teaching and also how the OU might be structured in order to address those elements.

A key starting point was that the aim was not just to produce a correspondence approach to higher education. Instead the full range of components that made up a university were considered. That meant as a consequence that a more complex framework was required in designing The Open University than had been applied in established correspondence education. In keeping with the original concept of a "University of the Air" the Planning Report highlighted a role for broadcast as a replacement for the lecture of more conventional higher education. The report noted the "logistical advantages" of the lecture with broadcast providing scope to improve on quality and economies of scale so that they were "likely to achieve results at least as good as and often better than those secured by the normal live lecture". Six educational aims were assigned to the use of broadcast. Three being of benefit to a general audience:

a) Allow presentation of topics with high impact.

b) Share cultural value to a wider audience.

c) Promote awareness of the possibilities of higher education.

Together with three being of benefit to those who became students:

d) Support preparation so that there would be lower "fall-out" rate of those who do then sign-up.

e) Avoid the need for students to travel to attend events.

f) Help students to feel part of the university and in contact with its staff.

The use of broadcast was only seen as one element in the OU approach to teaching, albeit one that attracted attention in establishing the OU. Those who founded the OU were clear that it was "neither practically possible nor pedagogically sound to rely on broadcasting as the principal or exclusive means of instruction in an operation designed to provide disciplined courses of university level" (HMSO, 1969, p6). Instead it was proposed that a staff body be established that could support the mix of broadcast with printed materials and also offer the students the support that was needed. Some guidance for the aims of the OU came from work in the US, and several early appointments and visiting consultancies drew on experiences in independent and correspondence study there. While it is hard to give single credit for such work it is worth noting one contribution as described by Moore (1990) of the previous experience by Charles Wedemeyer in attempting to establish an Articulated Instructional Media project (AIM) at the University of Wisconsin to offer degree level education at a distance. Quoting Wedemeyer, Moore states that AIM "was an experimental prototype with three fatal flaws: it had no control over its faculty, and hence its curriculum; it lacked control over its funds; and 
it had no control over academic rewards (credits, degrees) for its students. The implications were clear: a large-scale, non-experimental institution of the AIM type would have to start with complete autonomy and control" [quoted in Moore, 1990, p. 292.]. Whether drawn directly on this experience or not, these three points do appear to have been considered in the formation of the $\mathrm{OU}$ as an autonomous entity structured to have academic faculty, independent finance, and awarding powers.

The structure was also planned in greater detail with the Planning Report proposing six different substructures, four areas that were considered essential, with two further areas seen as desirable.

The four core areas can be summarised as:

1. Central administrative office - to take control of the finances and to recruit and administer the students.

2. Academic departments - faculty on academic contracts that would be responsible for the content as a whole.

3. Specialised academic related staff to support the methods of teaching and media required, including broadcast through the BBC.

4. Administration of the part-time tutors and student counselling services, this was seen as being distributed across regions and nations.

The further two areas outlined in the Report were:

5. An operational research unit to be "established as an early priority" to undertake studies in support of new methods of teaching.

6. To set up its own publications department.

The division of labour in the structure that was planned was very much reflected in the eventual setup of the university, with integration of each area around the structuring of a "course team" approach to ensure that responsibility for the student experience, and the materials and media that supported it, would be a shared one. The ambitious aim for the OU was to establish four foundational courses for study across key disciplines, to support those with different media, including broadcast, and to offer those courses to 25,000 learners within two years of being established. The "course team" emerged as a concept that has since become a core element of the university's success and provided resilience to several challenges. That the concept was not fully formed was acknowledged by those who worked on it at the time as "an enormous bit of improvisation" and the contributions needed had to rapidly evolve, "nobody for example realised that you actually had to have professional editors" (Mike Pentz, Dean of Science, speaking in 1979) (Open University, 1979). The lessons of that early stage were that not only did content have to be produced, it also needed to be integrated into a learning experience and the students supported to achieve the right outcomes. The role of research and evidence was important and from an early stage data on student performance was included, through surveys of students at scale and targeted projects to understand student needs. 


\section{Formation of IET, the Institute of Educational Technology}

In forming The Open University as a complex organisation there was recognition that there was a need to invest not only in the discipline-based materials needed by the students, but also in the way that learning would operate for the students. The Planning Report had noted the need for research into educational technology: "We propose, therefore, that an operational research unit of the University be established as an early priority in order to undertake the necessary studies. Indeed the continuation, as an integral feature of the University, of experimental work particularly in relation to the learning process may eventually prove to be one of the University's distinctive contributions to education generally." (HMSO, 1969, p16). (Experimentation certainly did continue; the current and next planned phase for such work is discussed in the next chapter.)

The OU was established in 1969, gaining its charter in April 1969, and during its first year a decision was made to establish a unit to bring together staff development and research. A paper provided to the Council of the University (Perry, 1969) stated that the "role of The Open University as a major innovator in education" required "not only academic personnel distinguished in their respective disciplines, but also staff with special skills in all the modern methods of educational technology." The paper therefore "recommended the immediate establishment of an Applied Educational Sciences Unit" with responsibilities that included "service for course teams and contributing towards a professional development programme for University staff." Research was flagged as likely to increase as "academic staff become more conversant with the techniques of educational technology, and the workload with course teams decreases". These actions are also reflected in a later book considering the early days of the OU authored by the first Vice Chancellor, Walter Perry, saying "The Planning Committee had recommended most strongly an ongoing programme of research into the operation of the University. ... I therefore proposed that the Department of Applied Educational Sciences should be combined with the group of Research Officers into a single Institute. ... My suggestion was accepted ... and the Institute of Educational Technology was born." (Perry, 1977, p81). The role of the Institute of Educational Technology was summarised in a further paper to Senate in 1970 in terms of the impact needed on $\mathrm{OU}$ instructional materials:

“(1) They will all have been extensively tested and validated on representative samples of students and volunteers.

(2) They will make provision for individual differences, by permitting some choice of route and rate towards the course objectives.

(3) They will utilise the various media and supporting services to best advantage.

(4) They will demand participation from the student and will provide him with frequent assessments of his progress. 
(5) They will provide the Course Teams with continuous diagnostic feedback as a basis for remedial guidance, revision and recycling." (Open University, 1970, p1).

The formation of IET provided one indication that the OU considered that the way in which it taught needed to both be different to conventional approaches and to evolve and change over time. The aim was to be innovative and to embrace the use of technology where it was appropriate to do so.

\section{Persistent approach in developing distance education}

The Open University has operated for 50 years on the basis that students can be enabled to learn at a distance. The very existence of the university is a testament to its persistence in ensuring the approach works. Having started by recruiting to its then maximum capacity of 25,000 students in 1971, it is the UK's largest university in terms of numbers of students taught, both expressed as a total number and as full time equivalent. Over its 50 years more than 2 million people have become its students, and nearly 500,000 have received qualifications. In 2018 it had over 170,000 students studying (though that is below the peak of over 250,000 in 2011/12). In addition, it offers free learning to over 7 million learners through its open educational resources (described further in forthcoming chapters) and a further 2 million supported by FutureLearn (Chapter 6). This is all in the context of a university that was created in uncertainty and amid questions as to whether it was offering education to an appropriate group of people.

\section{Fundamentals for learning at scale}

From its start The Open University adopted an open approach to higher education that may still be seen as going against accepted practice that access to such education is to be earned through achievement in earlier assessed education. The university system that developed in the western world and dominates in the world today is based on a model of scarcity. That model sees access to recognised education as less available as the levels increase. In particular postsecondary education is positioned as being for a privileged few. In relatively recent times that was reflected in a very clear way in the design and operation of the education system in the UK, with growth in the last 50 years to give access for more of the population into tertiary education. In 1960 approximate 5\% of the population would attend university between the ages of 17-30, by 1970 this had risen to nearly $15 \%$ where it remained throughout the 70 s and 80 s. Then in the 1990s there was new policy and ambition with a push to attain $50 \%$ that led to increases in the numbers entering tertiary education, with $49 \%$ being claimed in 2017 (Guardian, 2017). 


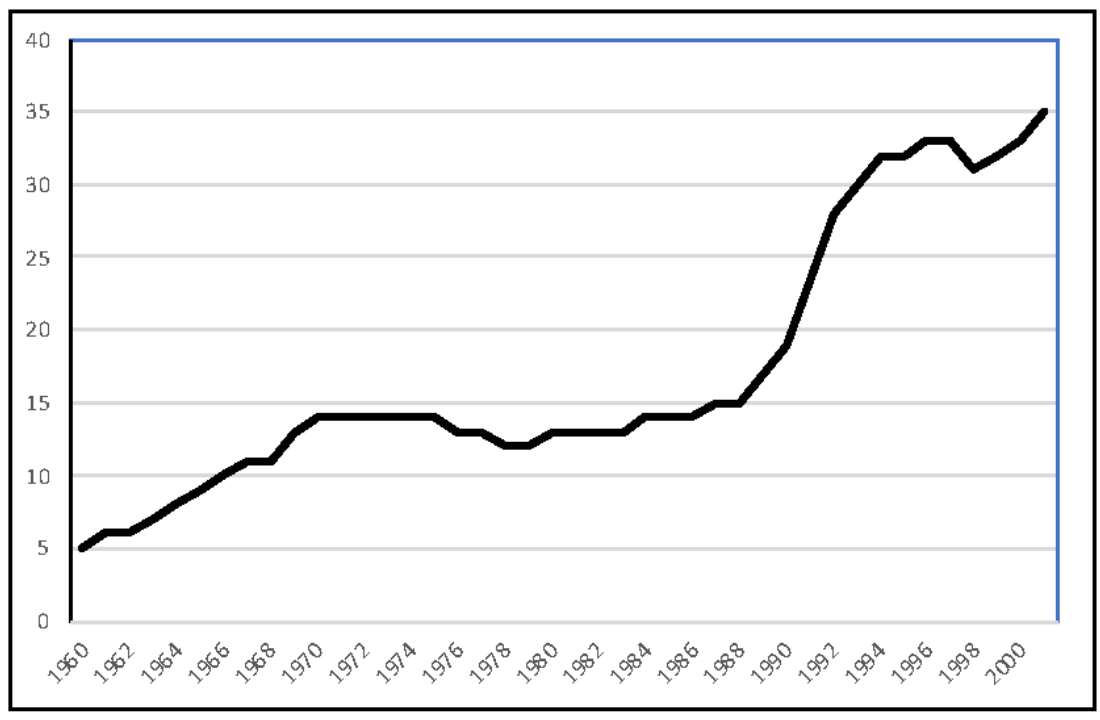

Figure 2.1: Age Participation Index of 17-30 year olds in university (\%) 1960-2001: Adapted from Chowdry et al (2010).

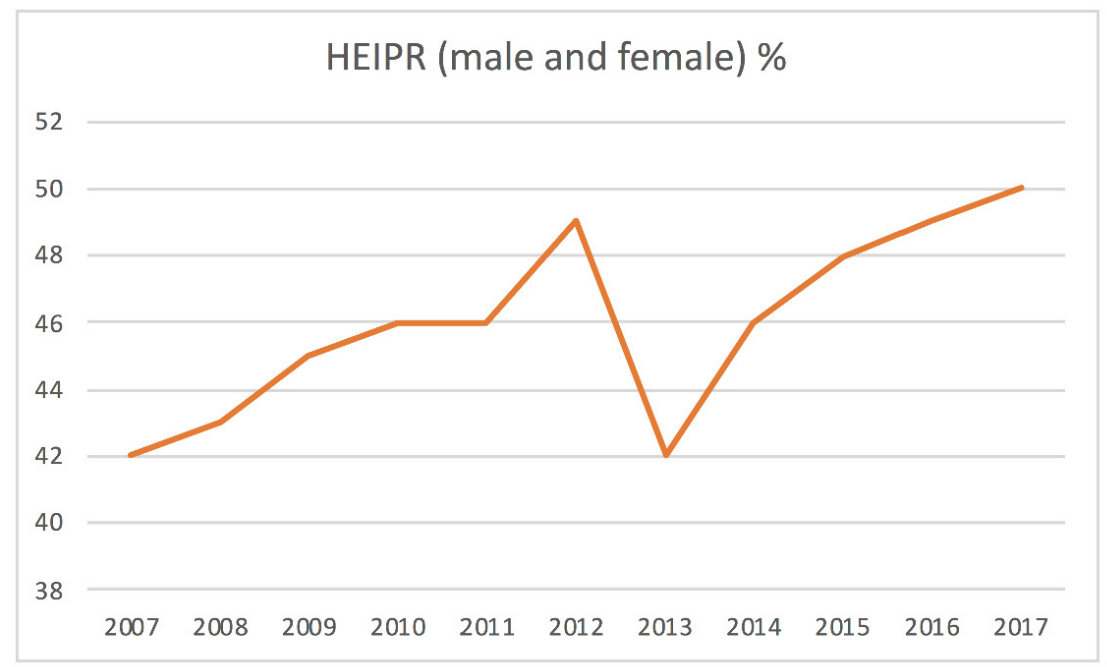

Figure 2.2: Higher Education Initial Participation Rate for England. Data from the Higher Education Statistics Agency (HESA) 2018. 
The earlier trend towards greater entry to university in England is shown in Figure 2.1 above (adapted from Chowdry et al. (2010), using data from Finegold (2006)) and more recent data from HESA(2108) in Figure 2.2. Even with increasing attendance there was a need to diversify provision (Finegold, 2006). With $50 \%$ provision there remain both "the other half" and those that had left education before it expanded. Yet the dominant model remains one in which university study is undertaken during a period away from home and within a separate process from that of 'work'. Privilege remains built into the system with access gained on prior attainment, by seeking to filter out those who are not suitable at the start of the process. Prior qualifications are required with a requirement for "2 A-levels" an underlying assumption for eligibility for study.

The OU represents a persistent approach to push back at this existing model, through understanding both some of the truth in assumptions, and in looking at how to address them. A clear example of persistence is support for entry into study. An open entry approach to study inevitably means that on some measures The Open University will not look as successful as other universities. Past success is a good indicator of future success and at the point of entry that is most efficiently judged through grades achieved in previous formal examinations, with a correlation between those and future results identifiable, though weak (Birch and Rienties, 2014). While accepting such a link provides an overall picture, it is not the case at an individual level that learners with low or no previous qualifications will not succeed. Indeed the idea that there is a "limited pool of ability" has been rejected in previous reviews of higher education (Dearing, 1997).

\section{Do qualifications matter?}

Being open entry and operating at scale means that it is possible to see the different performance of those from different backgrounds. Four lessons have been learned here:

1. Anyone may succeed. So using data such as prior study and economic background to determine whether someone should be allowed to try to study means that some of those who would have succeeded will have been excluded.

2. Prior qualifications are an indicator for initial success. Perhaps not surprisingly those who have already shown success in earlier study are more likely to succeed, however for all abilities of student there are similar points where they struggle and determination is needed.

3. Once success in OU study has been achieved then previous study history is almost irrelevant. This means that it is vital to support students to achieve that initial success and to set them on the path to success.

4. The measure of success is not necessarily the same for the student and the institute. The focus institutionally and culturally is often on a qualification. 
This is reflected back if students are asked to state their aims. Overwhelmingly (nearly $90 \%$ of) OU students will indicate that their aim is to achieve a degree. However, in practice students may gain advancement or satisfaction without meeting the degree. In the past this was built into the highly modular study structure of the OU. Current structures risk labelling those who leave prior to the degree as failures at system level (so that in league tables or funder progress models these are not successes), and at institutional level (with metrics set on final outcomes rather than progress). Unless success is identified at the student level this risks individuals seeing themselves as failing, despite possibly having achieved academically more than they had ever done before.

\section{Modelling performance}

One revealing indicator for the way in which different factors impact on the success of students is the analysis of the cohorts of students used to help judge whether a module at The Open University is performing as expected. Such analysis allows comparison with historic measures of performance for student completion and attainment, adjusted to allow for the impacted of the student body that is recruited. While demographics for an individual are not a sufficient reason to infer their success or failure, at scale such demographics can help us understand whether a group as a whole is likely to perform better or worse. An historic factor analysis has been used for the last 10 years to take into account all measures available. Some of the factors considered are shown in Table 1.

Table 1: Factors in predicting student performance in Open University modules (information provided by Vicky Marsh and Jim Peard of The Open University).

\begin{tabular}{|c|c|c|}
\hline $\begin{array}{l}\text { Student motivation } \\
\text { factors (demographics) }\end{array}$ & $\begin{array}{l}\text { Module factors } \\
\text { (choice of study) }\end{array}$ & $\begin{array}{l}\text { Previous student } \\
\text { experience }\end{array}$ \\
\hline $\begin{array}{l}\text { Occupation } \\
\text { Gender } \\
\text { Age } \\
\text { Credit transfer }\end{array}$ & $\begin{array}{l}\text { Discipline area } \\
\text { Level } \\
\text { Credits from the module } \\
\text { Number of assessments in the } \\
\text { module } \\
\text { Credits gained in same } \\
\text { discipline area } \\
\text { Credits gained at same level } \\
\text { of study }\end{array}$ & $\begin{array}{l}\text { Previous OU study } \\
\text { Previous study success } \\
\text { Previous educational } \\
\text { qualifications }\end{array}$ \\
\hline
\end{tabular}

The details of the modelling are interesting, though not important in the context of this chapter. Here the importance is that the 10 years of data show a high level of consistency for the factors that emerge and in differences between initial 
study and continued study. For initial study one of the top factors is highest previous educational qualification gained before study, for continuing students this does not appear as a top 10 factor in the analysis of statistically significant factors in determining student success. For new students three of the other top 10 factors are also related to their background while for continuing students there is only one remaining demographic factor, relating to the market segment that they come from rather than their personal background. In simple terms this implies that from OU data it is only at the start of study that likely success can be judged from personal background or achievements in earlier education. Once study has got underway then previous successful study within the OU is the strongest predictor. This indicates the short-sightedness of building a system of higher education that first filters out people based on already achieved qualifications, rather than giving them a chance to develop and prove themselves.

\section{Commencing study}

The difference in achievement in early study that does depend on previous preparation has also been addressed in the OU approach with initial study seen as part of learning to learn rather than as a way to filter out. The OU has

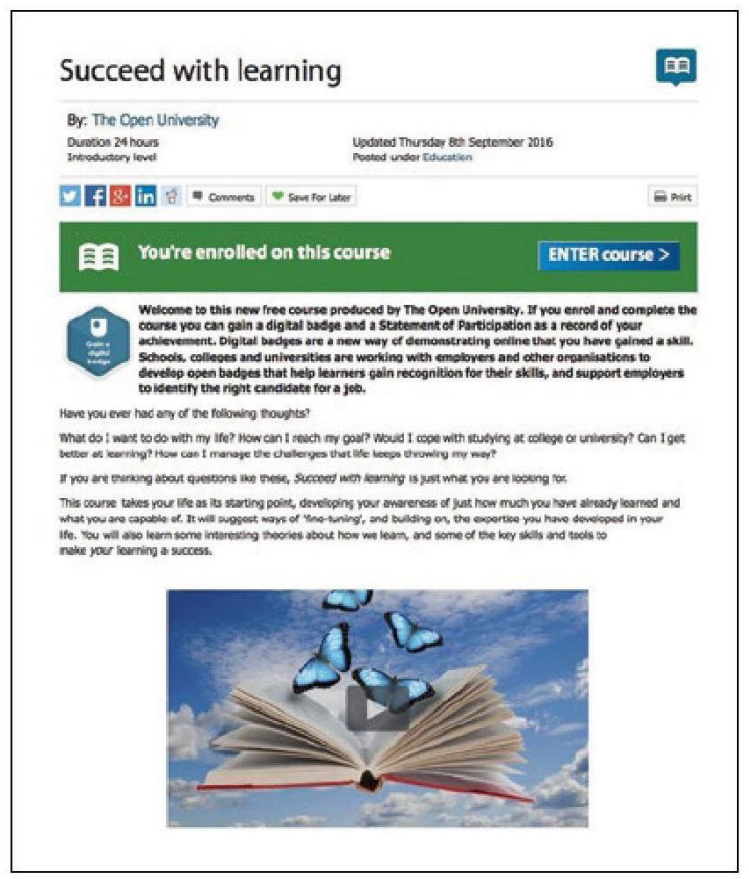

Figure 2.3: Available Badged Open Course: Succeed with Learning. 
persistently looked to provide routes to support early study. Initially this was through gateway study with partner organisations, notably the National Extension College, and through foundation stages in the OU degrees. More recently it has supported those returning to education through programmes of Openings courses and, currently, through a range of Access provisions. Some of those changes reflect development over time, others the response of the OU to external factors. The value of the Openings approach was also demonstrated when it was used to support students facing difficulty in their study in US Community Colleges. In the Bridge to Success project (Law et al., 2012), material that was part of two Openings courses was reworked into open educational resources to support Learning to Learn and Succeed with Math. These resources were then used flexibly across a range of contexts by US Community Colleges, universities and other organisations such as charities. The success of these alternative bridging models both to inspire educators (Coughlan et al., 2013) and provide support for students (Pitt et al., 2013) showed that this is often an under-supported area where approaches in place in the OU can transfer successfully into other contexts. Updated versions of both of these courses remain freely available as Succeed with Learning and Succeed with Maths with badged recognition (Badged Open Courses) on the OpenLearn site (Law, 2016), Figure 2.3.

The current range of Access modules were designed to fit with the need for students in some parts of the UK to be eligible for loans to pay for study. This meant that the modules needed to become larger and eligible for accreditation as pre-university study. The reworking also allowed other changes so that the modules contain additional online study and revised assessment (Hills et al., 2018), both of which prepare the students more fully for further study (Butcher et al., 2018). While it might be tempting to see such Access modules as the poor relation in contrast to the main stream modules, in practice they are among the most highly rated modules for student satisfaction and have shown their value in improved performance, especially for those otherwise at risk, such as those with low previous educational qualifications. This shows action by the OU to give students, who would otherwise be in categories that might struggle with initial study, a route that can lead them to build up success with the OU and so improve their chances of further success.

\section{Bricolage: Experimental approach to the learning experience}

The OU supports learning at a distance for higher education in a changing environment both in terms of what students want and in how the technology can support it. By necessity the OU has needed to operate an experimental approach; initially in taking new steps into how to provide the scale that is needed, then to retain an innovative approach that evolves to make use of technology for educators and for students. Major changes have included adoption of online virtual learning environments, use of online conferencing 
and remote connections, and changes in how we assess students. These though have not come in isolation as one-off decisions, rather in each case there is a history of experimentation at a range of scales and of learning from external experiences.

\section{Materials, cascaded support and feedback}

The concept of materials as the basis for learning may initially feel wrong. That we can package up learning seems to draw us back to the Nurnberg funnel concept that we can simply provide the content and pour it in. The materials may have moved on from written texts to also include the use of other media such as broadcast, video and audio however if it is all there and can be sent in a big cardboard box then the student will be able to spend the time and come back having "learnt" it all. This, of course, is not the case and the idea of materials-based learning is not that the materials are everything, rather that they can provide an alternative to the high-contact approach and synchronous presentations seen in more traditional lectures. Furthermore the design of the experience around the materials can build in the tasks, activities, support and assessment that make learning more likely and do this in a way that can be scaled.

The design process for OU courses contained two innovations in particular. The first innovation is that the teaching component should be available within the content: while content is not necessarily king it is a vital component. The second innovation is that content would be closely supported by feedback to the learner.

Feedback has for some time been an unacknowledged element in education and learning. In Hattie's analysis (Hattie, 2008) of effects of educational innovations, feedback is ranked as one of the areas having highest likely impact, and yet this is a factor that often is either ill-defined or side-lined. The National Student Survey includes a rating for feedback. Assessment and feedback is the area in which the OU has consistently ranked highly in comparison with other UK universities. In 2019, it came first out of all higher education institutions with $85 \%$ compared to an average of $73 \%$ (OfS, 2019). For feedback to be so strong in the case of an institution where feedback has to be given at a distance is perhaps at first surprising. However this has been achieved through integration of feedback into the learning design and assessment of materials, to ensure feedback is provided at a scale that allows sufficient time and attention to be given to the individual.

Feedback at the OU operates both through its role in the design of the learning experience and in how support is provided. Materials are designed to be interactive and involve the learner in line with the materials-based approach. The materials need to talk to the learner, and ask them to be active. This can be achieved in print-based content by a combination of the language used and 
the addition of accompanying motivating activities, such as through watching broadcast programmes or through experimental kits. With availability of online content, interactivity is also through online activities, discussions and simulations, as part of the designed overall approach so that the structure of the module is made an active experience.

The second aspect of how feedback operates at the OU is through the cascaded model of support. An Associate Lecturer will typically support a group of approximately 20 people who are studying a module together. They will have started at a common point and while there will be flexibility in terms of day to day pacing of study there will be key synchronisation points where students need to supply material for assessment. Such assessment is designed to help the students gain understanding and receive feedback through the marking of the work. Typically the work will also be marked and form part of the assessed outcome of the module, however by design it is acting in a formative way to help the student learn. The tension between marked work and feedback is well recognised in the literature with studies showing that feedback is the more important component for learning, while marks provide the higher motivation to complete, in line with other work where optional components for learning inevitably have a lower priority.

\section{Distance learning works}

Working in education or training it is very common to come across the attitude that there is nothing as good as face-to-face teaching and that anything that differs from getting people in the same place to learn is a compromise. This belief has been challenged over the years with correspondence education developing from the 18th century with the University of London, being the first higher education teaching establishment to provide correspondence education at scale. With the formation of The Open University in 1969, as described earlier, there was appreciation that the range of tools available could move on from correspondence models to alternative ways to connect with students. Overall it represented a rethinking of the approach to learning, considering the "Educational Technology" of how people learn.

The method that emerges from this work is one that values all the components in student activity. These include designing shared events, such as broadcasts, that motivate student engagement; providing content direct to the student, as written texts and other media (including physical experimental kits) that incorporated all that was needed to cover the required syllabus; and building in support through contact with tutors either face-to-face or through technology, such as via telephone. Bringing the whole method together was an approach to assessment that built in staged feedback from tutors that is tailored to the individual student and advises them how to improve, whilst ensuring a rigour that could be compared directly to other approaches to higher education. 


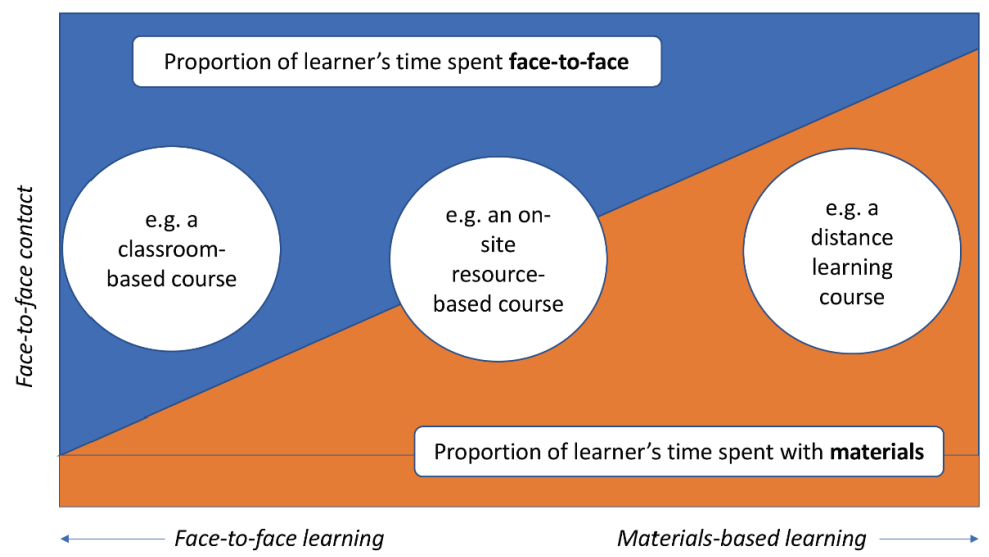

Figure 2.4: Balancing face-to-face contact with materials. Adapted from Rowntree (1997).

This approach has had various names, and there have been changes over time. The OU for some time used the label of "Supported Open Learning". This emphasised the support and contact component, as differentiating the approach from a correspondence based approach, and acknowledged the core role of the tutor in providing greater resilience and the ability to cope with the individual differences in the needs of the learners. A further label that has been given is of "Materialsbased learning' (Rowntree, 1997). This emphasises the use of materials in place of contact that is designed to share knowledge. The concept of material based learning is one end of a continuum (see Figure 2.4 - based on the introductory figure given by Rowntree, 1997) that goes from traditional classroom based instruction through to learning at a distance from materials. Note that in Rowntree's model the contact does not fall to zero in how he considers materials, i.e. he is assuming that some contact will always be part of the teaching process.

The balance between a structured approach to the design of teaching and the dialogue and freedom to consider ideas was considered by Michael Moore during his time at the OU in the 1970s and 1980s and was described later under the label of Transactional Distance (Moore, 1993). This contained a rethinking of the distance element of distance education away from physical distance to measure instead how close the approach was to being able to transact the education through dialogue. In this model low transactional distance would be achieved through free-flowing dialogue between the learner and the educator which gave considerable autonomy to the learner. Higher transactional distance would be constrained provision of ideas in a tight structure that did not allow for the learner to take control. In conventional teaching, high transactional distance would occur in a content heavy lecture that offered little expectation of questions, low transactional distance in a one-to-one personal tutorial 
that allowed open discussion. The theory did not make any judgement as to which was the better approach, rather it highlights for distance education that the challenge is to develop ways to vary the transactional distance and understand how these can operate in combination to benefit the learner.

For the OU the challenge of course design recognised that the learner needed to be able to be supported so that materials guided them to achieve the original intentions stated in the Planning Report to address the "limited opportunities for education, determined by social, economic and political factors" (HMOS, 1969, p.2).

\section{The role of evidence}

The fourth component of the Beyond Prototypes model is evidence. This, perhaps more than anything, is how The Open University differentiated itself from other universities when it was formed and it has remained a key part of the OU's approach. Evidence of the impact of teaching was needed to show that new approaches resulted in a university that met quality requirements. This meant developing understanding of the processes of the university and how they could be justified, monitoring the performance of its students, and finding out what was the students' own view of their experience. This last component was very much an innovation and was supported through a process that included large scale surveys, which in turn influenced the development of the National Student Survey adopted in the UK (Richardson, Slater and Wilson, 2007). The Institute of Educational Technology has played a central role in the gathering of relevant research, in the application of that research to cases inside and outside the OU and in addressing the challenge of communicating an evidence base.

An evidence-based approach to decision making has often been advocated. Arguably this has been less apparent in education and in particular higher education where status and tradition can dominate over innovation and evidence. The revolution provided by the OU meant that it pushed against that tradition and needed to show that it could function, and meet similar quality measures to other universities, while working with a broader body of students and at a larger scale than other universities. The starting points rethought the approach away from contact-based teaching to one where content and support could operate together to provide the learners with all that they needed. As discussed in McAndrew (2010), a useful metaphor for the time (1960s) was of being able to support the lighthouse keeper who was physically remote from many resources, though with access to communications technology in the form of television and telephone.

\section{Data wranglers}

One of the challenges of gathering large amounts of data is the time and expertise required to interpret it. A focus on understanding the impact of different 
media on students had been part of the remit of IET first through an Audio Visual Media Research Group and then a more targeted Programme on Learner Use of Media, established in 1990 (Weinbren, 2015). In 2009 the focus moved from considering media to looking at data itself. At that time the Student Statistic and Survey Team had achieved a partial success in making available summarised date and then giving online access to data for deeper inspection. This was supported by training and opportunities to request further analysis. Even with careful planning the reality was that use of data was not uniform across the OU and there was a perception that data was more often used to consider the local concerns of an individual module rather than the priorities of the university or faculty. While the module will always be a key element of experience, common challenges such as retention and student performance required a more coordinated approach.

An academic team was created that would work in a targeted way both within faculties and across faculties on shared priorities. The focus on data was recognised in the chosen name for the team, Data Wranglers (Clow, 2014), and in initial targets, to make sure that clearly communicated reports that highlighted the key metrics needed by all parts of the university were provided. These developed over time to also include comparisons between different parts of the university and easy to interpret indicators of relative performance, one example being thumbs-up/thumbs-down signs to quickly show differences between different parts of the university for measures of student performance and satisfaction.

A role that developed out of the Data Wrangling approach, and linked to their typical position as academics also carrying out research inside and outside the university, was the provision of thematic reports initiated in 2016 (Rienties et al., 2016). These reports have covered a mix of OU-specific topics, such as understanding the different registration points a student passes through while studying, and wider issues, such as the role of summative and formative assessment and approaches to feedback.

\section{Summary}

In this chapter the Beyond Prototypes model, developed to analyse the processes of innovation in technology-enhanced learning and consider what can help enable successful TEL innovation, has been applied to one of the largest on-going educational technology projects, The Open University itself. The chapter has shown how the four aspects of innovations in the Beyond Prototypes model (the TEL complex, persistent intent, bricolage and evidence) can be successfully applied to The Open University. McAndrew has argued that complexity was a fundamental aspect of starting The Open University. In going beyond a correspondence approach, the original concept of "the University of the Air", with broadcasting playing a key role, was viewed very broadly and in developing an ambitious and complex structure for the OU, its planners learnt 
from relevant work in the US. So the first section considers how complexity was addressed by those working to bring The Open University together as they thought through how teamwork, and the role that educational technology needs to play could work in practice.

A clear example of persistence, the second component of the model, is continuing open entry, requiring support for entry into study. In discussing this aspect of the university, OU data was drawn on which shows it is only at the beginning of a student's study trajectory that their likely success can be judged from their background and or earlier achievements. Once a student's journey is underway the best predictor of success is previous successful study in the OU.

The chapter has also illustrated how the OU had to take an experimental approach, (applying the third factor, bricolage) from the very beginning; partly to address the complexity challenge: in working out how to operate at such scale; how to structure itself; how to remain innovative in a changing world and how to make best use of technology for educators and for students. Examples include providing online virtual learning environments, online conferencing and remote connections, and making changes to assessment. One of the innovations in the design of OU courses is that content is closely supported by feedback to the learner, and in this context, the chapter has shown how feedback operates both through the design of the learning experience and in how support is provided.

Evidence is the fourth aspect of the framework and this is shown to be a particularly important part of the OU's approach and significant in the distinctiveness of the OU. In this respect IET work has been key and has collected evidence on student learning and attitude from the very beginning. One example of the role of evidence is the use of 'Data Wranglers'.

\section{A model for now}

The Open University was intended to be different; to try out new ideas and go beyond prototypes to operate at scale. The OU of fifty years ago was a challenge to a model of limited access to university. Now such a model seems even more unsuited for the situation we are in. Wider access to education has not led to equal access with participation from those disadvantaged remaining behind on several different measures such as POLAR, and ethnicity. Passing on costs to the learner in the form of expensive loans has also created pressure on those who are already earning, in particular leading to a fall in the numbers of those studying part-time.

Taken together this means that there is a greater need to consider the ways in which we can effectively operate a larger scale, lower cost, university system for those who have a wider background of prior qualifications. This is the current challenge facing the whole sector. It also characterises the challenge that the OU has faced for 50 years. 
Many aspects of this challenge, and how it is being addressed, are discussed in the following chapters. In particular, the next chapter, Chapter 3, considers the future of teaching and learning at scale.

\section{References}

Birch, D.M. and Rienties, B. (2014). Effectiveness of UK and international A-level assessment in predicting performance in engineering. Innovations in Education and Teaching International, 51(6) pp. 642-652.

Butcher, J., Clarke, A., Wood, C., McPherson, E. and Fowle, W. (2018). How does a STEM Access module prepare adult learners to succeed in undergraduate science? Journal of Further and Higher Education. 43(9) pp. 1271-1283.

Clow, D. (2014). Data wranglers: human interpreters to help close the feedback loop. In: LAK' 14 Proceedings of the Fourth International Conference on Learning Analytics And Knowledge, ACM Press, pp. 49-53.

Coughlan, T., Pitt, R. and McAndrew, P. (2013). Building open bridges: collaborative remixing and reuse of open educational resources across organisations. In: 2013 ACM SIGCHI Conference on Human Factors in Computing Systems 'changing perspectives' (CHI 2013), 29 Apr - 02 May 2013, Paris, France, pp. 991-1000.

Dearing (1997). Report of the National Committee of Inquiry into Higher Education. [Online] https://www.leeds.ac.uk/educol/ncihe/natrep.htm

Finegold, D. (2006). The Roles of Higher Education in a Knowledge Economy. [Online] http://www.heart-resources.org/wp-content/uploads/2015/10/ The-Roles-of-Higher-Education-in-a-Knowledge-Economy.pdf?e4e997

Guardian (2017). Almost half of all young people in England go on to higher education. [Online] https://www.theguardian.com/education/2017/sep/28/ almost-half-of-all-young-people-in-england-go-on-to-higher-education

Hattie, J. (2008). Visible Learning: A Synthesis of Over 800 Meta-Analyses Relating to Achievement. Routledge Taylor \& Francis Group.

Hills, L., Clarke, A., Hughes, J., Butcher, J., Shelton, I., and McPherson, E. (2018). Chinese whispers? Investigating the consistency of the language of assessment between a distance education institution, its tutors and students. Open Learning: The Journal of Open, Distance and e-Learning, 33(3) pp. 238-349.

HMSO (1969) The Open University: Report Of The Planning Committee To The Secretary Of State For Education and Science. London: Her Majesty's Stationery Office.

Law, P., McAndrew, P., Law, A., Warner, K., Runyon, J., Lascu, D., and Muramatsu, B. (2012). A bridge to success. In: Cambridge 2012: Innovation and Impact - Openly Collaborating to Enhance Education, a joint meeting of OER12 and OpenCourseWare Consortium Global 2012, 16-18 Apr 2012, Cambridge, UK. 
Law, P. (2016). Digital badging at The Open University: recognition for informal learning. Open Learning: The Journal of Open, Distance and e-Learning, 30 (3): 221-234.

McAndrew, P. (2010). Defining openness: updating the concept of "open" for a connected world. Journal of Interactive Media in Education, 2010(10) pp. $1-13$.

Moore, M.G. (1990). International Aspects of Independent Study, in The Foundations of American Distance Education: A Century of Collegiate Correspondence Study, Watkins, B and Wright S.J. (Eds), Kendall/Hunt, Dubuque, Iowa, pp. 287-386.

Moore, M.G. (1993). Theory of transactional distance In D Keegan (ed) Theoretical Principles of Distance Education pp. 22-38 Routledge, New York.

OfS (2019). National Student Survey results spreadsheets 2019: 2019 NSS summary data. [Online] https://www.officeforstudents.org.uk/advice-andguidance/student-information-and-data/national-student-survey-nss/getthe-nss-data/

Open University (1970). Proposal for the Institute of Educational Technology. Paper to Senate, S/II/8. Milton Keynes: Open University.

Open University (1979). Open Forum 41 1979: The First Ten Years. Transcript available from [Online] https://www.open.ac.uk/library/digital-archive/ exhibition/53/theme/2/page/3

Perry, W. (1969). Establishment of an Applied Educational Science Unit, Council Paper C/II/3. Milton Keynes: Open University.

Perry, W. (1977). The Open University: History \& Evaluation of a Dynamic Innovation in Higher Education. Open University Press, UK.

Pitt, R., Ebrahimi, N., McAndrew, P. and Coughlan, T. (2013). Assessing OER impact across organisations and learners: experiences from the Bridge to Success project. Journal of Interactive Media in Education, article no. 17.

Richardson, J.T.E.; Slater, J.B. and Wilson, J. (2007). The National Student Survey: development, findings and implications. Studies in Higher Education, 32(5) pp. 557-580.

Rienties, B., Edwards, C., Gaved, M., Marsh, V., Herodotou, C., Clow, D., Cross, S., Coughlan, T., Jones, J., and Ullmann, T. (2016). Scholarly insight 2016: a Data wrangler perspective. Open University UK.

Rogers, E.M. (1995). Diffusion of Innovations. Free Press; 4th edition.

Rowntree, D. (1997). Making Materials-based Learning Work. London: Routledge Falmer

Scanlon, E., Sharples, M., Fenton-O’Creevy, M., Fleck, J., Cooban, C., Ferguson, R., Cross, S. and Waterhouse, P. (2013). Beyond prototypes: Enabling innovation in technology-enhanced learning. Milton Keynes: Open University.

Weinbren, D. (2015). The Open University: A History. Manchester: Manchester University Press. 